\title{
Radar/rain-gauge comparisons on squall lines in Niamey, Niger for the AMMA
}

\author{
B. Russell, ${ }^{\mathrm{a} *}$ E.R. Williams, ${ }^{\mathrm{b}}$ M. Gosset, ${ }^{\mathrm{c}}$ F. Cazenave, ${ }^{\mathrm{c}}$ L. Descroix,${ }^{\mathrm{c}}$ N. Guy, ${ }^{\mathrm{d}}$ T. Lebel, ${ }^{\mathrm{c}}$ \\ A. Ali, ${ }^{\mathrm{e}}$ F. Metayer ${ }^{\mathrm{c}}$ and G. Quantin ${ }^{\mathrm{c}}$ \\ ${ }^{a}$ Department of Atmospheric, Oceanic and Space Sciences, University of Michigan, Ann Arbor, Michigan, USA \\ ${ }^{\mathrm{b}}$ Parsons Laboratory, Massachusetts Institute of Technology, Cambridge, Massachusetts, USA \\ ${ }^{\mathrm{c}}$ LTHE - Université Grenoble 1/IRD, Grenoble, France \\ ${ }^{\mathrm{d}}$ Atmospheric Sciences, Colorado State University, Fort Collins, Colorado, USA \\ 'AGRHYMET, Regional Center, Niamey, Niger
}

\begin{abstract}
Massachusetts Institute of Technology C-band radar observations are integrated with rainfall measurements from an extensive network of gauges in Niamey, Niger, West Africa, for the African Monsoon and Multidisciplinary Analysis (AMMA). The large number of gauges available enabled $Z_{\mathrm{e}}-R$ power-law relationships for the convective and stratiform regions of individual squall lines. The $Z_{\mathrm{e}}-R$ relationships based solely on radar measurements directly over the gauges were developed for the estimate of rainfall and attendant latent heat release (by other AMMA investigators) where gauges were unavailable. The low prefactor values of the $Z_{\mathrm{e}}-R$ power laws relative to like values for $Z-R$ disdrometer power laws have contributions of order $1-2 \mathrm{~dB}$ from the use of the lowest beam tilt $\left(0.57^{\circ}\right)$ and $\sim 1-2 \mathrm{~dB}$ by the radar reading low. (The sphere calibration and the Tropical Rainfall Measuring Mission TRMM - radar calibration are inconsistent at the 1-2 dB level for unknown reasons.) Radar/gauge comparisons are also shown for individual storms. Accurate, unbiased results for the convective regime require adjustment of the radar-to-gauge radials for attenuation. Beam filling problems and aliasing issues can often be identified in the case of outlier points. Copyright (c) 2010 Royal Meteorological Society
\end{abstract}

KEY WORDS C-band radar; rainfall; $Z_{\mathrm{e}}-R$ relation; attenuation

Received 11 December 2008; Revised 15 October 2009; Accepted 23 October 2009

\section{Introduction}

This study is concerned with C-band radar measurements of rainfall with key assistance from an extensive network of 56 rain-gauges in Niamey, Niger, as a contribution to the African Monsoon and Multidisciplinary Analysis (AMMA). The main objectives of this study are the optimization of rainfall measurements in both the convective and stratiform regions of West African squall lines in a meteorological regime that is decidedly continental and baroclinic. The main provision of the study is quantitative guidance on the treatment of radar reflectivity data for rainfall (and attendant latent heat release) over areas substantially greater than afforded by the rain-gauge coverage.

The usual practice in the radar measurement of rainfall is the use of the filter paper technique or surface disdrometer measurements to compute simultaneously the reflectivity $Z\left(\Sigma D_{i}{ }^{6}\right.$ in units of $\mathrm{mm}^{6} / \mathrm{m}^{3}$, where $D_{i}$ is a raindrop diameter, and the summation is over all raindrops within the sample volume), and the rainfall rate $R$ (in $\mathrm{mm} / \mathrm{h}$ ), to regress these two quantities, and then to

\footnotetext{
${ }^{*}$ Correspondence to: B. Russell, Department of Atmospheric, Oceanic and Space Sciences, University of Michigan, Ann Arbor, Michigan, USA. E-mail: bbrussel@gmail.com
}

use the resulting best fit $Z-R$ power law together with calibrated radar measurements of $Z_{\mathrm{e}}$ (in place of $Z$ ) to infer the rainfall rate on the ground (Austin, 1987). The most favourable circumstance of this comparison is that $Z$ and $R$ are measured simultaneously and over the same volume $\left(\sim 100 \mathrm{~m}^{3}\right)$. The great majority of $Z-R$ relationships in the literature (Battan, 1973) are born from this approach. An alternative procedure, and the one pursued here, involves the use of surface rain-gauges to measure $R$ at multiple points and the radar to measure $Z_{\mathrm{e}}$ as closely as possible above the individual gauges, and to regress the two quantities to determine a $Z_{\mathrm{e}}-R$ power law. The scatter in such plots at high time resolution is ordinarily substantially greater than in the $Z-R$ disdrometer plots, and as a consequence, such diagrams are rarely shown in published papers (e.g. Zawadzki et al., 1986), and when they do appear, they are not regressed. Since the ultimate radar measurement of rainfall is made with the radar beam (typical sampling volume $10^{7}-10^{8} \mathrm{~m}^{3}$ ) and not with a disdrometer or rain-gauge at a point, the understanding of the scatter of points in a $Z_{\mathrm{e}}-R$ plot has much practical importance. To optimize the measurement of rainfall, it is essential to distinguish random deviations (sampling representativeness, drop size variability) from systematic ones, including drift in the radar calibration, incomplete beam 
filling (Rogers, 1971; Zawadzki, 1982; Rosenfeld et al., 1992), attenuation (Hitschfeld and Bordan, 1954; Geotis, 1975; Hildebrand, 1978; Atlas et al., 1993; Bénichou, 1995; Delrieu et al., 1999), and evaporation/break-up of raindrops between the radar sample location aloft and the gauge at the surface. In the present study, beam-filling and attenuation effects are given particular attention. If the systematic variations can be studied and tamed, the random variations will tend to cancel out, particularly when integration in time is practiced, typical in both hydrological (stream flow) and meteorological (storm integrations of rainfall and latent heating) applications.

The $Z-R$ and $Z_{\mathrm{e}}-R$ approaches discussed here are intimately linked of course, and if the radar is well calibrated, and if the Rayleigh regime condition $(\lambda \gg D)$ is satisfied, and if the pulse resolution volume (PRV) is homogeneously filled with rain, and if the attenuation by intervening rain is negligible, and if the PRV is collocated with the disdrometer/gauge, and if drop size distribution does not vary in the vertical, then the $Z-R$ power law based on the disdrometer fit should match with the $Z_{\mathrm{e}}-R$ fit for the radar/gauge comparisons. The fulfilment of all these physical conditions is rarely if ever achieved, but the comparison of power-law fits remains a valuable check on overall consistency.

Power-law regression in radar meteorology is more than brute-force empiricism. Raindrops are very closely spheres, and reflectivity and rainfall rate are both power laws of raindrop diameter. Furthermore, systematic differences in power-law relationships have been demonstrated between the convective and stratiform regimes (Tokay and Short, 1996; Atlas et al., 1999; Maki et al., 2001; Nzeukou et al., 2004; Moumouni et al., 2008). For all of these reasons, power laws are espoused again in the present study. An alternative approach to linking reflectivity and rainfall rate is the probability matching method (Calheiros and Zawadzki, 1987; Rosenfeld et al., 1993), but in this approach one loses sight of specific physical causes for systematic error (i.e. beam-filling, attenuation), and so is less preferred. Here it is shown that corrections for both beam-filling effects and C-band attenuation, particularly in the strongly convective portions of squall lines, lead to clear improvements in the radar measurement of rainfall.

\section{Methodology}

\subsection{MIT C-band radar}

The Massachusetts Institute of Technology (MIT) Cband Doppler radar has served as the transportable component of the MIT Weather Radar Laboratory for several decades. This Enterprise radar was acquired in the early 1970s for the Global Atlantic Tropical Experiment (GATE) where it was installed and operated on a ship off the west coast of Africa. The radar has seen service in many subsequent field projects, including Winter MONEX in Borneo, GALE in North Carolina (Engholm et al., 1990), DUNDEE in Darwin, Australia
(Williams et al., 1992), TOGA COARE (Rickenbach and Rutledge, 1998) and PACS (Yuter and Houze, 2000) on either side of the Pacific Ocean, in addition to projects with MIT Lincoln Laboratory (Williams et al., 1989a) on microburst detection in Alabama, Florida and New Mexico, and signal processing exercises for the Terminal Doppler Weather Radar, for which a new solid-state transmitter was installed. When the radar is between field programmes, its home has been atop the Green Building on the MIT campus where it has been operated alongside the S-band radar for aligned beam studies on C-band attenuation (Geotis, 1975) and the radar cross-section of lightning flashes (Williams et al., 1989b).

The operating characteristics of the MIT radar are listed in Table I. The radar is currently equipped with SIGMET IRIS software for antenna control, transmit/receive, processing of data, and real-time display. For the AMMA field programme, the radar was operated with full volume scanning repeated at 10-minute intervals, initiated at the start of every hour. The fixed-beam A-scope display is also used with the radar parameters as input to perform radar calibrations, as detailed in the Appendix.

\subsection{The rain-gauge network, 'Square Degree'}

The network began as the EPSAT (Estimation des Precipitations par SATellite) network of recording rain-gauges and has been operating since 1990, allowing the study of the structure of the rain fields at the mesoscale and for different time scales (e.g. Le Barbé and Lebel, 1997; Ali et al., 2005; Balme et al., 2006). The AMMA-Catch Niger rain-gauge network was installed in 2004 for the AMMA Enhanced Observation Period (EOP, see next section), to provide for comprehensive and concurrent observations of the free atmosphere, the boundary layer and the ground rain fields. Two additional recording raingauges were installed in 2007 to make the network denser eastward from the MIT radar. Altogether, the network represents a total of 56 automatic recording rain-gauges over an area of about $16000 \mathrm{~km}^{2}$. These individual sensors are of the tipping type, with a resolution equivalent to $0.5 \mathrm{~mm}$ of rain. The time series of bucket tips are recorded with digital data loggers (manufacturer: Oedipe - Elsyde, Paris, France, or $\mathrm{HoBo}$ - OnSet, Pocasset, Massachusetts, USA). The locations of the subset of 56 gauges used in this study are displayed in Figure 1 below.

As explained above, the automatic rain-gauges record the times of occurrence of bucket tips; for the

Table I. Operating parameters for MIT C-band radar in Niamey, Niger.

\begin{tabular}{ll}
\hline Transmitted peak power & $250 \mathrm{~kW}$ \\
Pulse width & $1 \mu \mathrm{s}$ \\
Horizontal beam width & $1.4 \mathrm{deg}$ \\
Vertical beam width & $1.4 \mathrm{deg}$ \\
Antenna gain & $40 \mathrm{~dB}$ \\
Pulse repetition frequency & $950 \mathrm{~Hz}$ \\
\hline
\end{tabular}




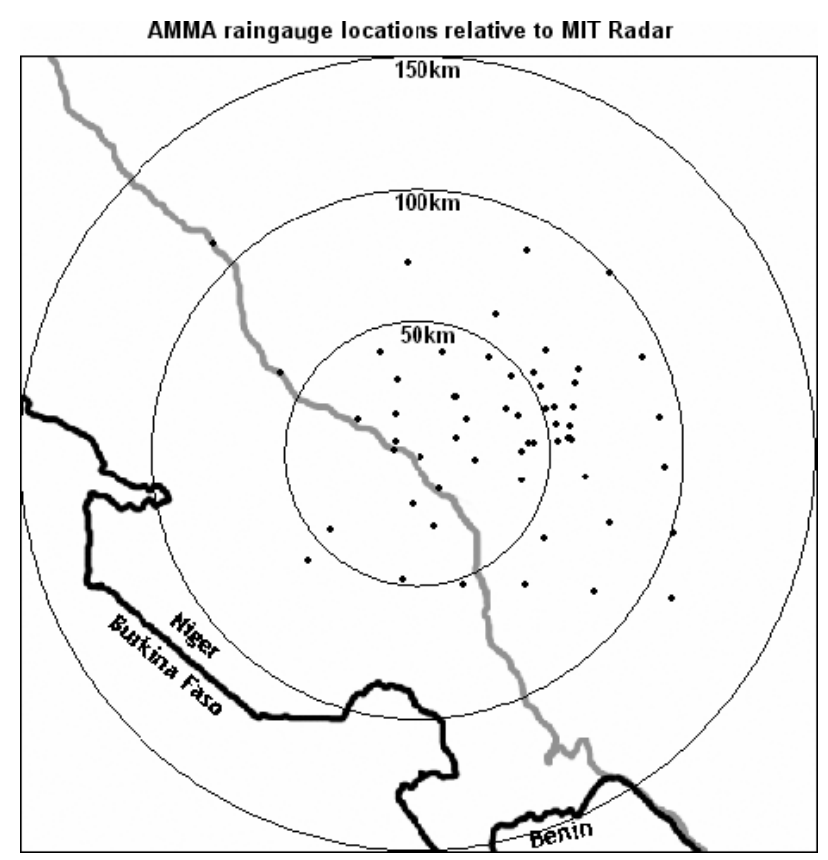

Figure 1. Map showing the AMMA rain-gauge network used in this study and the MIT radar location near the Niger River. Note that the majority of gauges lie to the east of the radar, in the direction from which the squall lines generally originate.

gauges installed in Niger (model PM 3030, from Précis Mécanique, France) the collection area is $400 \mathrm{~cm}^{2}$ and the tips occur for every $0.5 \mathrm{~mm}$ of accumulated rainfall. As illustrated in Figure 2 below, the tip occurrences (black ticks) are very frequent in the initial convective regime and comparatively rare beneath the trailing stratiform region.

To provide a rainfall rate appropriate for 5-minute time intervals (half the radar sample interval), a conversion scheme is necessary. The basic principle is to count the number of tips, $N$, that occur during each 5 -minute interval. The rainfall rate (in $\mathrm{mm} / \mathrm{h}$ ) is then retrieved from the equation: $R=(N-1)^{*} 0.5 * 12$. An interpolation scheme is required to take into account the contribution, in a given time step $j$, of the bucket which began to fill in the previous step $(j-1)$, and of the bucket which began to fill during step $j$ but which will tip later. The entire algorithm is summarized below:

Call $t_{j}$ the regular times, and call $P_{j}$ the rain amount between $t_{j}$ and $t_{j+1}$ (i.e. the regular time step $j$ of interest)

Call $T_{i}$ the times of tip, with $T_{k}$ the first tip which occurred after $t_{j}$

(1) To calculate $P_{j}$, we start from the last tip $\left(T_{k}\right)$ that occurred before $t_{j}$

(2) Then we check the length (or duration) of the interval $T_{k}-T_{k-1}$

If $T_{k}$ is greater than $t_{j+1}$, then the rainfall accumulation for the period $j$ is :

$$
P_{j}=R R_{k}\left(t_{j+1}-t_{j}\right) /\left(T_{k}-T_{k-1}\right)
$$

where $R R_{k}$ is the rain amount recorded by the gauge for the tip that occurred at $T_{k}$. In general $R R_{k}$ is equal to the bucket size equivalent in $\mathrm{mm}$ of rainfall i.e. $0.5 \mathrm{~mm}$, corrected for calibration if needed. Otherwise $P_{j}$ is incremented by $R R, n$ times, until we reach a time $T_{k+n}$ which is greater than $t_{j+1}$.

In that case:

$$
\begin{gathered}
P_{j}=R R_{k} \frac{T_{k}-t_{j}}{T_{k}-T_{k-1}}+\sum_{i=k+1}^{k+n-1} R R_{i}+ \\
R R_{k+n} \frac{t_{j+1}-T_{k+n-1}}{T_{k+n}-T_{k+n-1}}
\end{gathered}
$$

The result of this transformation of tip history to rainfall rate by this algorithm can be seen in the example in Figure 2.

\section{Procedures with radar and rain-gauge observa- tions}

As a general strategy for this study, comparisons are made between radar and rain-gauges only in the lowest radar tilt (0.57 degree elevation angle), and only with radar range bins that are closest to the latitude/longitude of each raingauge (radar gate length equal to $0.250 \mathrm{~km}$ ). The main goal has been to characterize the rain with radar where we know it best, and that is over each gauge. No gridding of either reflectivity or rainfall rate is used in this study. For a gauge approximately $50 \mathrm{~km}$ from the radar, the reflectivity measurement is about $600 \mathrm{~m}$ above the gauge, so a typical elapsed time between the radar measurement of the rain aloft and its arrival at the gauge is $\sim 2$ minutes. The use of Sun tracking for antenna pointing accuracy, and the collection of radial data at the same azimuth for every full sweep, have both served to guarantee good spatial comparison between radar samples and gauges. The remainder of this section is concerned with various aspects of how the radar and rain-gauge data are treated for subsequent analysis.

\subsection{The distinction between convective and stratiform} rain

In many earlier radar/rainfall studies of convective and stratiform rain, the distinction and characterization of these two regimes is not always clear-cut. In contrast, in baroclinic West Africa, squall lines are the dominant mode of rainfall delivery (Le Barbé and Lebel, 1997), and they occur frequently throughout the wet season (June-September). During the three-month period of radar operation in 2006 (the AMMA SOP year), 30 squall lines were documented. During the less active season in 2007, 21 squall lines were observed. In the majority of these systems, the leading deep convective phase is rather easily and cleanly distinguishable from the trailing stratiform precipitation (see Figure 3, Leading convection). The transition region of squall lines is also readily apparent in the Plan Position Indicator (PPI) scans of radar reflectivity (see Figure 3, Transition minimum), and as a consequence, and in the interest of simplicity, 
07/22/2006 Rain Gauge : Djoure

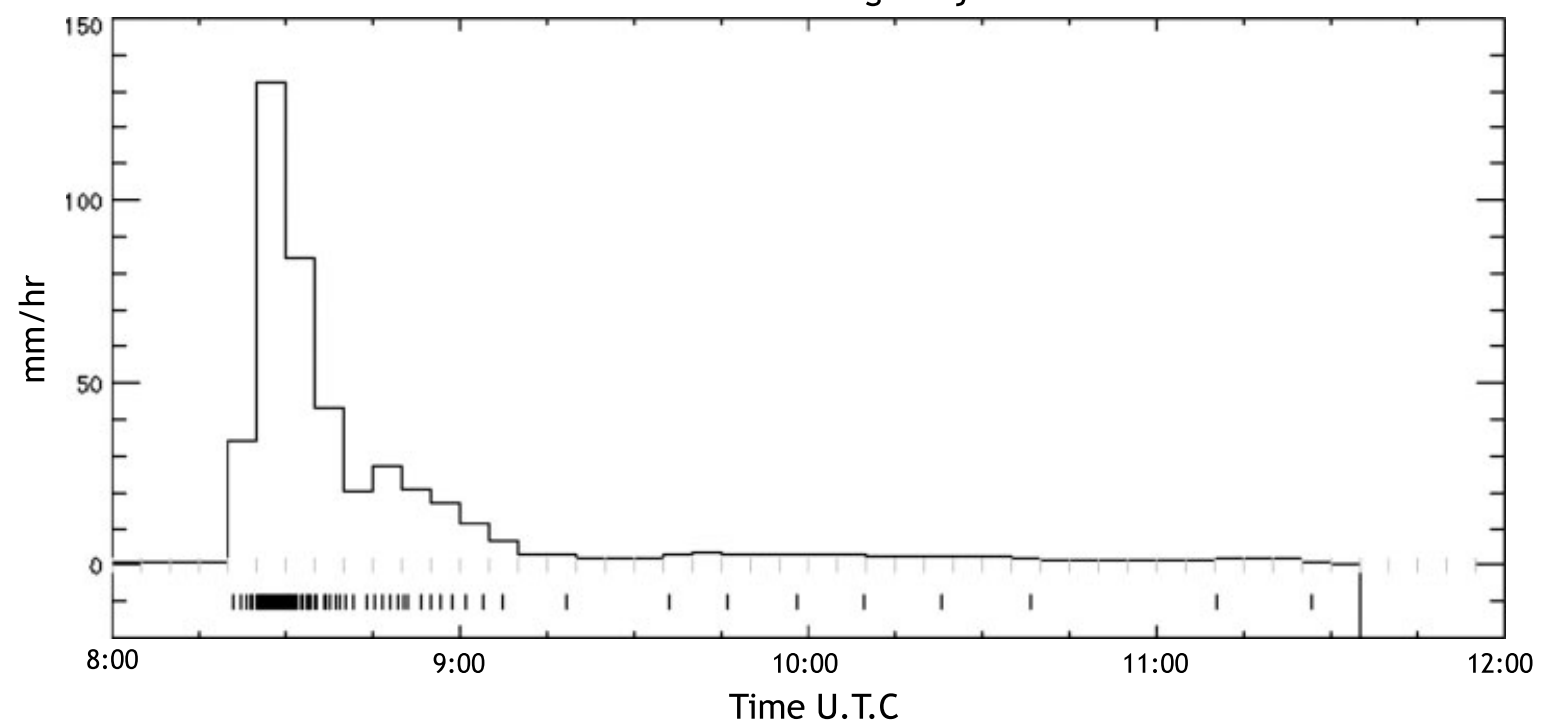

Figure 2. Time series of rainfall rate from a single rain gauge (here Djoure, as in Figure 3) for a sample squall line (22 July 2006). Black ticks: times of occurrence of the bucket tips corresponding to $0.5 \mathrm{~mm}$ rainfall ( $T_{i}$ in the text). Grey ticks: the regular 5 -minute time step intervals ( $t_{j}$ in text). Black line: the time series of rainfall rate in $\mathrm{mm} / \mathrm{h}$ with regular time steps (in this case 5 minutes).

we have assumed that the minimum reflectivity in the transition phase marks the end of the convective phase. The data points included in the stratiform phase are then defined starting from the maximum reflectivity within the next 40 minutes (four data points) following this transition minimum, until the end of the storm. The latter method of selection was aimed at capturing the radar bright-band phase of the stratiform precipitation. Based on our observations of Range Height Indicator (RHI) scans interspersed with the 10-minute volume scans during the field programme, a pronounced radar bright band was not formed until reflectivities had stabilized at a level which was typically between 5 and $15 \mathrm{dBZ}$ higher than the transition minimum, a process that took 20 to 60 minutes. An example of a PPI scan in the lowest radar tilt of the squall line on 22 July 2006 in which the convective and stratiform regions are well distinguished in both the radar and the rain-gauge records is shown in Figure 3. This figure relates the data from the radar and rain-gauge time series to their physical location of measurement at Djoure station as the squall line passes overhead. The time series of gauge rainfall rate (following procedures in section 2.2) and radar reflectivity overhead show excellent agreement. Notice that the reflectivity over Djoure station continues to rise steadily throughout the four data samples following the transition minimum, and that this minimum occurs at the same time in both radar and rain-gauge measurement.

3.2. Single-pixel pairing of gauge and radar measurements

The geographical coordinates of the radar antenna are $13.49^{\circ} \mathrm{N}, 2.17^{\circ} \mathrm{E}$. For every gauge in the network, an $X$ and $Y$ offset from the radar location were computed in UTM coordinates. The polar radar data are arranged in 360 rays that are 593 gates long. The first range gate starts
$1 \mathrm{~km}$ from the radar, and the last gate starts $149.75 \mathrm{~km}$ from the radar. The radar gate spacing is 250 metres (pulse repetition frequency $\mathrm{PRF}=950 \mathrm{~Hz}$ ).

The lowest antenna elevation angle (0.57 degrees) of the MIT radar produces the PPI scan nearest the ground, and was recorded every 10 minutes starting one minute after the 10-minute mark (e.g. 10:01:00, 10:11:00, 10:21:00, etc) requiring 30 seconds to make a 360 degree sweep. As explained at the beginning of this section, there is approximately a 2-minute delay between the time the radar measures the rainfall aloft, and the time the same rain reaches a gauge to be measured. Thus, the 5-minute rain-gauge data file from the five minutes before the estimated time of the radar measured rainfall reaching the rain gauge, and the 5-minute rain-gauge data file just after the estimated time of radar-measured rainfall reaching the ground were used to compute a 10minute average rainfall rate $(\mathrm{mm} / \mathrm{h})$ to compare to radar data (e.g. the mean rainfall rate for 10:10:00 - 10:15:00 and 10:15:00 - 10:20:00 is compared with radar data from 10:11:30 +/ -10 seconds), since the rainfall aloft that was measured by the radar in this file reached the rain gauge on the ground at approximately 10:14:00. The computed rain-gauge rainfall rates are then compared to the reflectivity measured in the radar gate directly above the gauge. Weighting the average of the two rain-gauge files to favour the first of the two (since the rain measured by the radar falls on the gauge slightly before the end of this file) was experimented with, but did not systematically improve results for radar-estimated rainfall totals, or the correlation coefficients $\left(\mathrm{r}^{2}\right)$ in the $Z_{\mathrm{e}}-R$ plots.

\subsection{Treatment of C-band attenuation}

Radar reflectivity measurements are corrected for path attenuation due to intervening rainfall using an iterative procedure. Each ray of reflectivity data is adjusted starting 


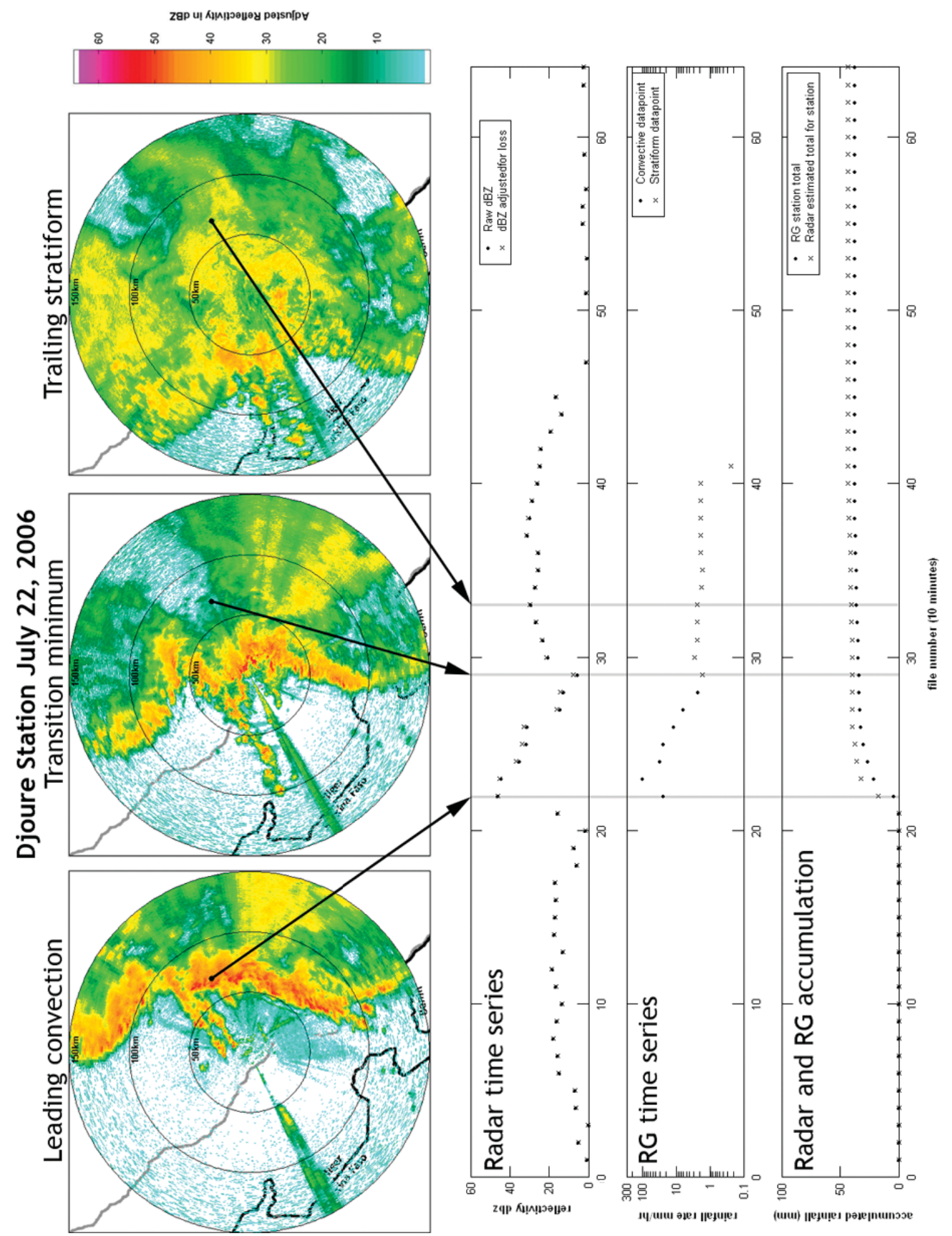

Figure 3. Radar PPIs and complete time series of local radar reflectivity $Z_{\mathrm{e}}\left(\mathrm{mm}^{6} / \mathrm{m}^{3}\right)$ and rainfall rate $R(\mathrm{~mm} / \mathrm{h})$ for the storm on $22 \mathrm{July} 2006$ for one rain-gauge (Djoure).

with the second gate in the ray and moving outward along the ray. Every gate's reflectivity is increased according to the total path attenuation between it and the radar, which is calculated after increasing the reflectivity of the previous gate in the ray. The following equations are used:

$$
\begin{aligned}
& d B Z_{\text {adj }(1)}=d B Z_{\mathrm{raw}(1)} \quad K_{\mathrm{path}(1)}=0 \\
& d B Z_{\mathrm{adj}(n)}=d B Z_{\mathrm{raw}(n)}+K_{\mathrm{path}(n-1)},[2: n: 593] \\
& K_{\mathrm{path}(n)}=\left(2 \cdot r_{\mathrm{gate}} \cdot A T T_{\text {prefactor }} \cdot Z_{\mathrm{adj}(n)}^{A T T_{\text {exponent }}}\right) \\
& \quad+K_{\mathrm{path}(n-1)},[2: n: 593]
\end{aligned}
$$

Attenuation-reflectivity relationships tested and compared in this study are illustrated in Figure 4. The Cifeli relationship (R. Cifeli, personal communication, 2008) was developed during the NASA Monsoon Multidisciplinary Analyses (NAMMA) experiment with observations from the National Aeronautics and Space Administration Tropical Ocean - Global Atmosphere programme (NASA TOGA) C-band radar.

This iterative method was tried initially using the reflectivity attenuation $(K)$ relationship of Bénichou (1995), and then with that of Battan (1973), both times with moderately successful results. When Bénichou (1995) is applied, small pockets of high reflectivity 


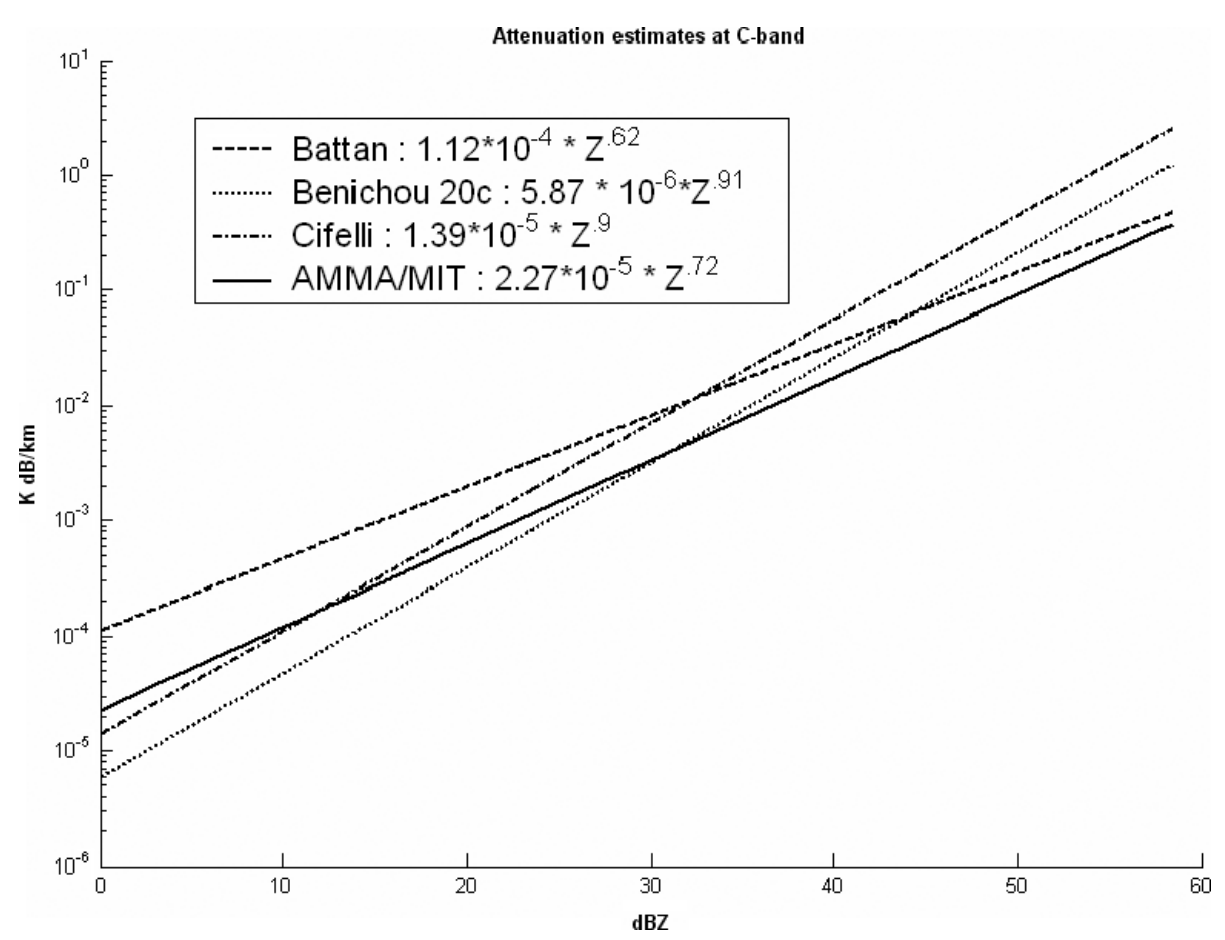

Figure 4. Attenuation relationships versus radar reflectivity for C-band from the literature and as evaluated and used in the present study (AMMA/MIT) on the basis of the analysis of attenuation 'shadows' cast by convective cells on the quasi-uniform stratiform region.

( $>50 \mathrm{dBZ}$ ) cause the iterative procedure to become unstable and adjusted path attenuation along the ray crossing a high reflectivity pocket will become infinite. In contrast, when the Battan (1973) relationship is used, rays with long paths through low to moderate reflectivity will cause the iteration to become unstable and adjusted path attenuation to grow without bound. In addition to this, attenuation 'shadows' were clearly visible in the large homogeneous stratiform areas of adjusted data behind small pockets of high reflectivity ( $>50 \mathrm{dBZ}$ ). These long radials of low stratiform reflectivity originating behind the most intense leading convective cells are useful indicators of whether reflectivities through long paths of widely varied reflectivity are being over- or under-corrected. Thus it was concluded that the Bénichou (1995) method was over-correcting for high values, and the Battan (1973) method was both over-correcting for low to moderate reflectivity values, and under-correcting for high reflectivity values.

To overcome this problem, a reflectivity-attenuation relationship close to Bénichou (1995), but providing for less attenuation at high reflectivity paths ( $>50 \mathrm{dBZ})$, and more attenuation at low to moderate reflectivity paths, was applied to the data. It was observed that this relationship did not cause the instabilities seen using the two previous methods, but was still not adequately correcting for attenuation in very high reflectivity ( $>50 \mathrm{dBZ}$ ).

With the proper balance established between attenuation through high and low reflectivities, the prefactor of the relationship was then increased in small increments $(\sim 10 \%)$ until under-corrected attenuation in large stratiform regions behind convective cells $>50 \mathrm{dBZ}$ was no longer obvious and calculations for all paths in the dataset remained stable. The final reflectivity-attenuation relationship used for this analysis was:

$$
K_{\mathrm{adj}(n)}=2.27 \cdot 10^{-5} \cdot Z_{\mathrm{adj}(n)} 0.72
$$

One strategy pursued in early stages of this investigation was an attempt to avoid the attenuation problem at Cband altogether by selecting radar-to-gauge radials that exhibited a path loss of less than $1 \mathrm{~dB}$ in constructing a $Z_{\mathrm{e}}-R$ relationship. Figure 5 illustrates why this strategy was workable only for the stratiform rainfall. Shown here is the characterization of each such radial (considering every 10-minute interval of the storm that the low-level sweep crosses a rain-gauge location) in one squall line storm (22 July 2006) as a combination of the estimated attenuation along the radial from radar to gauge and the adjusted reflectivity in the range bin directly over the gauge. The points are further distinguished as 'convective' (left plot) and 'stratiform' (right plot) following the rules noted earlier. All storm days exhibited similar behaviour to that shown in Figure 5. Note that the great majority of stratiform ray paths are characterized by path loss less than $1 \mathrm{~dB}$. Even though the stratiform region is large, the reflectivity there tends to be modest and so the corresponding attenuation, following the procedure described earlier, is also modest. Substantially larger path attenuations, up to $10 \mathrm{~dB}$ or more, are experienced in the convective regime, and the larger attenuations are particularly conspicuous for reflectivities $>40 \mathrm{dBZ}$. The impact of these large attenuations will be apparent when the radar/gauge comparisons are discussed in section 4, but the main result is that attenuation needed to be considered toward achieving accurate 

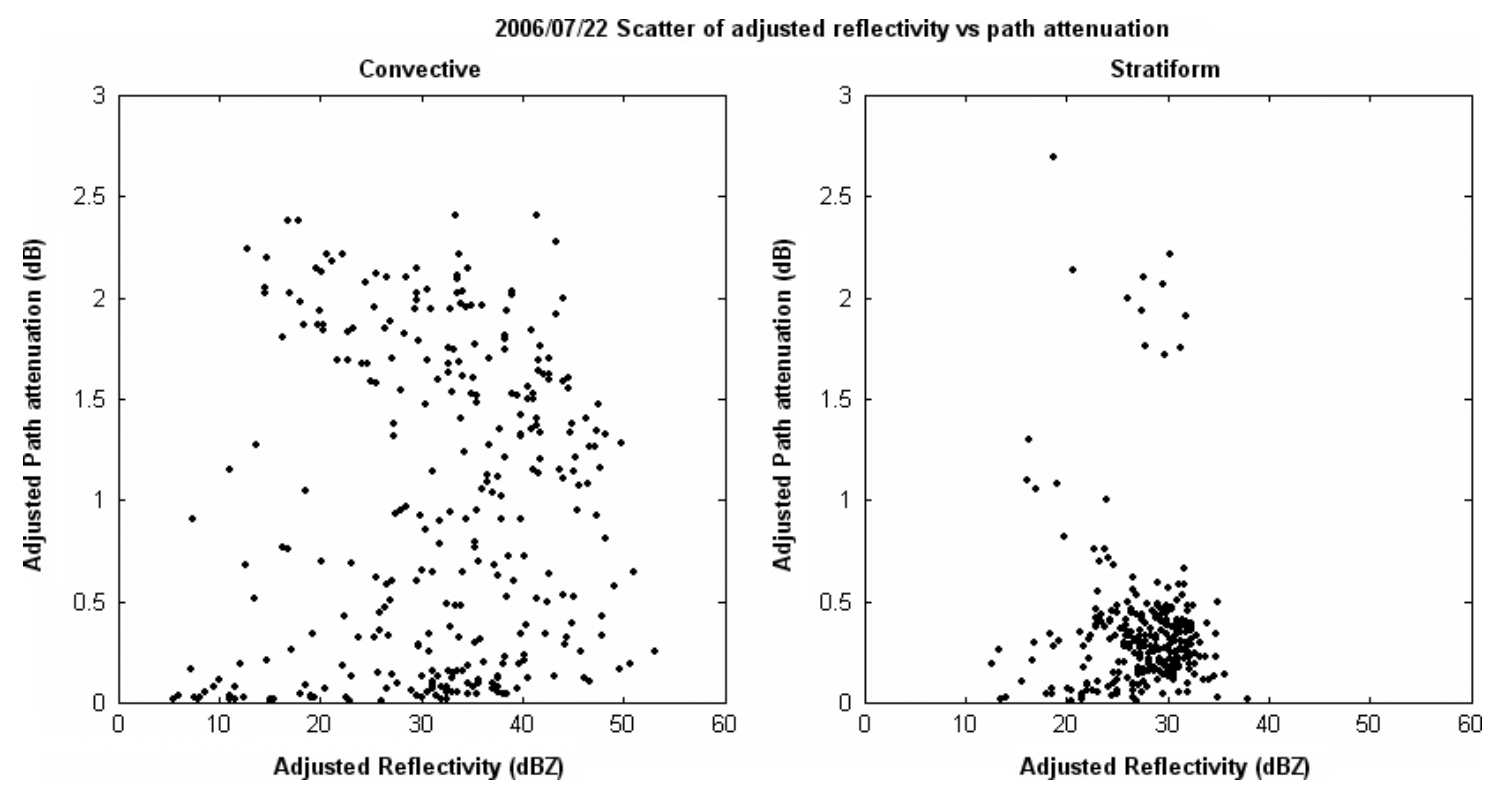

Figure 5. Characterization of radar-to-gauge paths for all sample pairs in the storm on 22 July 2006 based on radar scans at $0.57^{\circ}$ elevation angle. The attenuation-corrected reflectivity value over each gauge is paired with the attenuation correction along this path. Paths in the convective regime are on the left and paths in the stratiform regime are on the right.

comparisons between radar and gauges for the convective phase. This procedure not only gives a more accurate reflectivity value $Z_{\mathrm{e}}$ to compare with a rain-gauge reading, but it often provided a 2 - to 5 -fold increase in the number of convective data pairs for deriving a $Z_{\mathrm{e}}-R$ relation compared with the same process without adjusting reflectivities for path attenuation

3.4. Exclusion of reflectivity measurements with rain on the radome

One of the most debilitating forms of attenuation for a C-band radar comes from heavy precipitation falling directly on the radome itself. In dry conditions, we expect the radome attenuation to be a fraction of $1 \mathrm{~dB}$, but during heavy rainfall events, the layer of water running down the sides of the radome could be a millimetre or more thick. This greatly attenuates all radar observation made during this condition. To exclude measurements made under these conditions from the calculation of $Z_{\mathrm{e}}-R$ relationships, an average of the reflectivity value of the first gate in each ray (all radar data within a $1 \mathrm{~km}$ radius) is calculated for each 10-minute data sample. When this average value exceeds $36 \mathrm{dBZ}$ (a value observed to be a clear indicator of overhead convection), the corresponding data time is excluded from the $Z_{\mathrm{e}}-R$ calculation. Typically, this 'dead' period amounts to $10-20 \%$ of the radar/gauge data processing period for a given storm.

\subsection{General regression methods}

In arriving at power-law fits in $Z_{\mathrm{e}}-R$ plots generated in this study, one is faced with three options. One can regress reflectivity $Z$ against $R$, with $R$ the errorfree independent variable (the traditional approach in radar meteorology), or regress $R$ against $Z$, with $Z$ the error-free independent variable. Alternatively, one can treat both variables symmetrically, in a so-called total least squares (Nievergelt, 1994) and minimize the sums of the squares of the deviations perpendicular to the line of best fit. The recognition of the general problem of representativeness in this kind of comparison is tantamount to assigning errors to both variables. All power-law fitting in this paper makes use of the total least squares approach to calculate a $Z_{\mathrm{e}}-R$ power-law exponent $\left(b_{\text {convective }}, b_{\text {stratiform }}\right)$. The prefactors of the $Z_{\mathrm{e}}-R$ power laws are then calculated using the following equations to assure unbiased rainfall totals (section 3.7):

$$
A_{\text {convective }}^{\prime}=\frac{\sum Z_{\mathrm{e}_{\text {convective }}}}{\sum R^{b_{\text {convective }}}}, \quad A_{\text {stratiform }}^{\prime}=\frac{\sum Z_{\mathrm{e}_{\text {stratiform }}}}{\sum R^{b_{\text {stratiform }}}},
$$

The $Z_{\mathrm{e}}-R$ relationships used for this analysis can then be calculated using the following equations:

$$
\begin{gathered}
Z_{\mathrm{e}_{\text {convective }}}=A_{\text {convective }}^{\prime} R^{b_{\text {convective }},} \\
Z_{\mathrm{e}_{\text {stratiform }}}=A_{\text {stratiform }}^{\prime} R^{b_{\text {stratiform }}} .
\end{gathered}
$$

$A^{\prime}$ is typically only slightly different than the prefactor calculated using the total least squares approach, but serves to provide unbiased rainfall totals using the following equation for integrated bias (Steiner et al., 1999), where $R_{i}$ is the total:

$$
B=\frac{\sum_{i=1}^{n} R_{i}}{\sum_{i=1}^{n} G_{i}} .
$$

In this equation, $R_{i}$ is the total rainfall estimated for a gauge by the radar for an entire event, and $G_{i}$ is the total rainfall measured by said gauge for the entire event. 


\subsection{Development of $Z_{\mathrm{e}}-R$ scatter plots}

Scatter plots of radar-measured $\mathrm{Z}_{\mathrm{e}}$ versus gaugemeasured $R$ were prepared at the finest time resolution of the radar samples - 10 minutes. In such plots that included all data pairs, the conspicuous presence of outlier points was predominantly (though not exclusively) an indication that the radar estimates of rainfall were low in comparison to the gauges. These outlier points were notably more frequent in the convective regime than the stratiform regime. These points were tentatively attributed to the presence of reflectivity gradients and heterogeneously populated pulse resolution volumes (Rogers, 1971; Rosenfeld et al., 1992), and in many cases this assumption was later confirmed by the detailed examination of outlier points in both the radar observations (full scan analysis) and rain-gauge records. A filter was developed to eliminate these extreme outliers from the $Z_{\mathrm{e}}-R$ fits.

For every reflectivity-rainfall rate data pair considered for inclusion in the $Z_{\mathrm{e}}-R$ calculation, the change in rainfall rate measured by the rain-gauge since the previous data pair (10 minutes ago) was calculated by first converting the two rainfall rates to $\mathrm{dBZ}$ equivalents using the $Z-R$ relationship of $Z=239 R^{1.45}$ derived by Chamsi (1992) based on disdrometer measurements made earlier in Niamey in the convective phase. Points with a jump or drop of more than $10 \mathrm{dBZ}$ in 10 minutes were classified as gradient-region points, and not included in the final $Z-R$ calculation. In many cases these were clear outliers in the unfiltered $Z_{\mathrm{e}}-R$ diagram. Following the rejection of the 'gradient' points, a total least squares fit was performed on the remaining points for the convective and stratiform regions independently to determine power-law relations between $Z_{\mathrm{e}}$ and $R$.

To assure a strong signal-to-noise ratio on the radar measurements, all values less than $20 \mathrm{dBZ}$ were excluded from the comparisons, for both the convective and stratiform fits. For typical $Z-R$ relations (summarized in Table III) this $20 \mathrm{dBZ}$ cut-off is equivalent to about $0.5 \mathrm{~mm} / \mathrm{h}$ of rainfall rate, a modest level even in stratiform rain. It is also customary in published disdrometer results to exclude the values in very light rain, and one should also keep in mind that the lower the rain rate the less reliable the rain estimation from tipping-bucket gauges for 5-minute time steps.

\subsection{Radar-gauge comparisons for storm totals}

To assess the accuracy with which the single powerlaw relationships developed from the $Z_{\mathrm{e}}-R$ fits could work for the entire collection of rain-gauges, comparisons were made between radar and gauge for the entire gauge accumulation for individual storms. This test provided some measure of how well one could determine rainfall over an area substantially larger than that covered by the gauge network on the basis of the radar measurements alone. In these plots, the diagonal line represents perfect agreement between gauge (abscissa) and radar (ordinate).
Two measures of success were computed for each of these plots: the mean accuracy between radar and gauge ('Error' below), and the mean absolute value of the accuracy of each gauge (e.g. Smith and Krajewski, 1991; Steiner et al., 1999) between radar and gauge ('|Error|' below). These quantities are defined as follows:

$\overline{\text { Error }}=\frac{1}{n} \sum_{i=1}^{n} \frac{R_{i}-G_{i}}{G_{i}} \quad \overline{\mid \text { Error } \mid}=\frac{1}{n} \sum_{i=1}^{n}\left|\frac{R_{i}-G_{i}}{G_{i}}\right|$

where $R_{i}$ and $G_{i}$ are the rainfall determinations by radar and gauge, respectively.

\section{Results}

The procedures discussed in the foregoing section 3 have been applied to squall line storms in 2006 and 2007. Separate $Z_{\mathrm{e}}-R$ scatter plots, total least-squares fits, and radar/rain-gauge comparisons are produced for each day, for both the convective and stratiform regimes. A summary of all the days examined is shown in Table II.

Three individual days, one from each month in 2006 (22 July, 18 August and 8 September) have been selected for more detailed illustration, and are all included in Figure 6. These cases tend to be the stronger, longerlived squall lines, but serve to represent both the successes and limitations of our approach. Figure 6 shows the $Z_{\mathrm{e}}-R$ scatter plots for the convective and stratiform periods (two left-hand panels), and the radar/gauge comparisons for storm-integrated rainfall for the convective (third panels) and stratiform (right-hand panels) regimes. The individual points in the $Z_{\mathrm{e}}-R$ scatter plots represent radar/gauge pairs at 10 -minute resolution. The scatter is manageable and the correlation coefficients (with numbers of points in the fits in the range $\sim 150-300$, owing in large part to the large number of rain-gauges available), the $r^{2}$ values for best fit are in the range 0.70 to 0.85 . The power-law fits tend to follow the trends observed in $Z-R$ fits based on disdrometer measurements, to the extent that the prefactor in the power law for the stratiform regime is larger than that for the convective regime. At the same time, both prefactors extracted by these methods tend to be low (by a factor of $\sim 2$, or $3 \mathrm{~dB}$ relative to typical disdrometer analyses of power-law fits on $Z-R$ scatter plots, see also Table III).

When the radar/gauge comparisons are considered (two right-hand panels), it is clear that the stratiform cases for all days show a tighter grouping of points and a greater accuracy. Each plotted point represents the comparison at a specific rain-gauge for the accumulated rainfall for the entire storm. The convective cases show considerably greater scatter around the diagonal line of perfect agreement. It is important to note that a systematic bias (radar reading low) was present in earlier calculations (not shown) for which attenuation corrections along the ray paths to gauges were not implemented.

The radar/gauge comparisons for all convective regimes in all storms showed pronounced outlier points in the radar/gauge comparison plots, and considerable atten- 


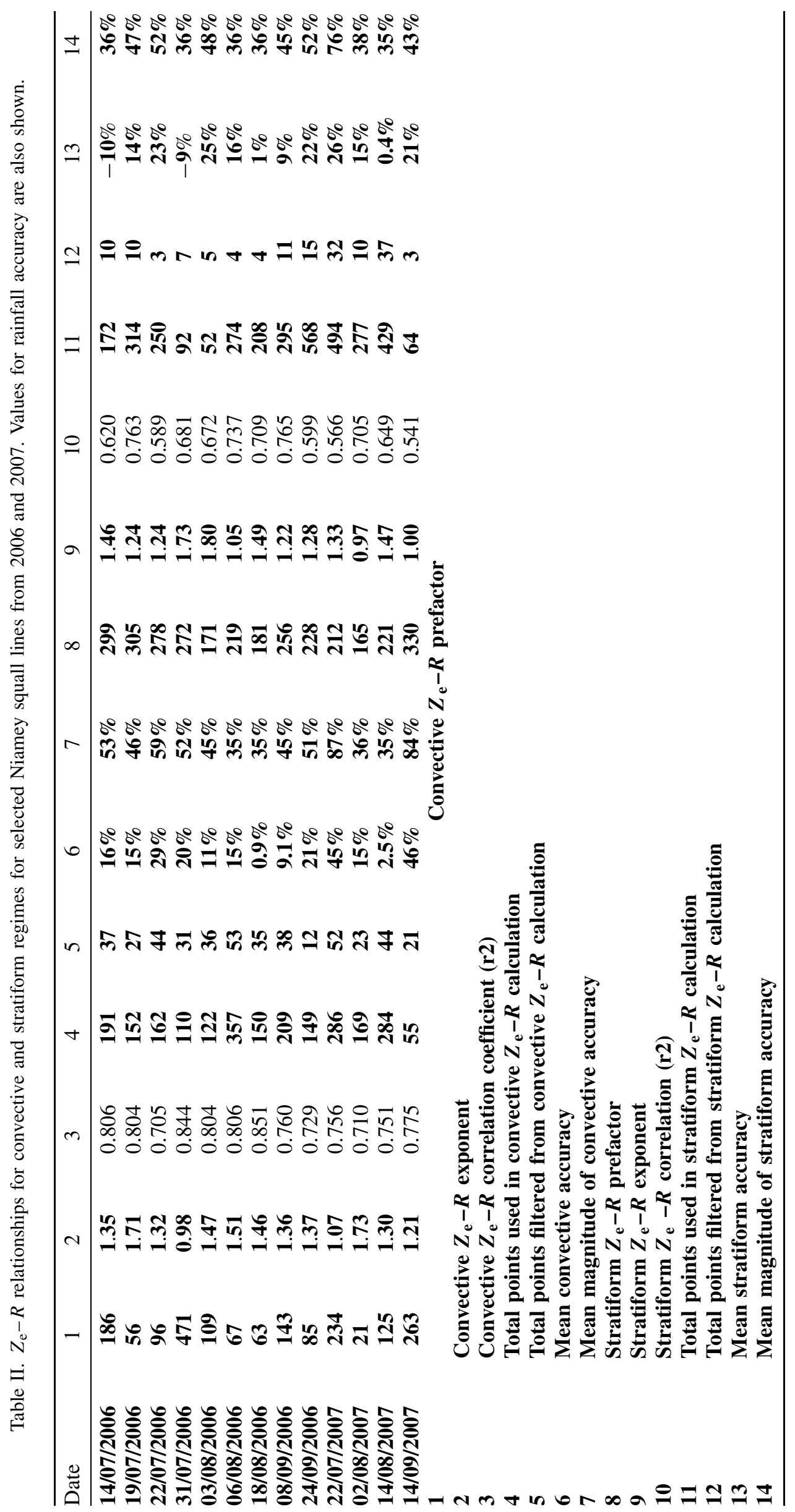


tion was devoted to scrutinizing these cases. It is clearly visible from examining the accumulation plots for the convective and stratiform regions in Figure 6 that there is much more scatter in the convective regime than the stratiform regime. This is expected since the stratiform regime is generally free of the large reflectivity gradients found in the convective regime. Examination of the data time series containing large, positive outliers showed that they originate from data samples when the rain-gauge was on the outer edge of a small pocket of very high reflectivity $(>60 \mathrm{dBZ})$. The outliers with very large bias from 22 July 2006 in Figure 6 are good examples of this phenomenon. Examination of the 5-minute rainfall rates used in those cases often showed a pair of one relatively low rainfall rate, and one very high rainfall rate $(>100 \mathrm{~mm} / \mathrm{h})$. Outliers with large negative bias originate from large path attenuation, either a long path through moderate reflectivity, or a path passing through a very high reflectivity ( $>60 \mathrm{dBZ}$ ).

In general, the stratiform region exhibits many fewer outliers than the convective, and is much more tightly clustered. The few outliers that do occur are attributed to data points being incorrectly classed as stratiform when in fact they are convective data. The algorithm used to classify these points works well, but is not $100 \%$ accurate. The fact that outliers in the stratiform regime tend to be negative instead of positive supports the idea that positive outliers originate from gradient regions, and negative outliers tend to come from insufficient adjustment of path attenuation.

The conspicuous outliers in the $Z_{\mathrm{e}}-R$ scatter plots came from measurements in regions with reflectivity gradients, and thus were excluded from the evaluations for best fit. These points represent more often than not a low reading of the radar relative to the gauge, and we have no easy means to correct the $Z$ values. If these 'bad' points are left in the radar/gauge comparison plots, then they result in anomalously large rainfall estimates.

After analysing the outliers from the convective events, it is clear that the discrepancy in rainfall between the radar estimate and gauge measurement for these points originates from one or two data points in the time series of that gauge. The data pairs causing these errors always involve one or the other of the following:

(1) Radar measurement coincides with a large gradient in rainfall directly over the gauge. This circumstance results in one of two things:

- The rain-gauge is recording extremely high rainfall rate (100-200 $\mathrm{mm} / \mathrm{h}$ and higher), and the radar reads a relatively low reflectivity. This leads to a positively biased outlier.

- The rain-gauge is recording relatively low rainfall rate and the radar reads high reflectivity (small cells of high reflectivity within the PRV but missed by the rain-gauge). This causes a negatively biased outlier.
(2) Radar measurement occurs through a long path $(10-20 \mathrm{~km})$ of high reflectivity $(\mathrm{dBZ}>50)$. This leads to a positively biased outlier

The outliers in the convective regimes in Figure 6 are all examples of these phenomena, with more than $90 \%$ of them being caused by measurements made in regions of large spatial gradients, or at times during large temporal gradients in rainfall (cause (1) above).

\section{Discussion}

The abundance of squall lines during the AMMA campaign, underlain by more than fifty rain-gauges (Figure 1), has enabled a good characterization of $Z_{\mathrm{e}}-R$ power laws for the convective and stratiform regions of individual storms. The challenging aspect here is that C-band attenuation, substantial reflectivity/rainfall gradients and the general radar representativeness of the 'point' rain-gauge measurement must all be contended with in interpreting the results. (Despite the large number of gauges, the mean distance between gauges in the AMMA network is of the order of a thunderstorm diameter, and perhaps an order of magnitude greater than the size of strong precipitation shafts in the cores of the storms.) Because the attenuation and sampling factors in the radar measurements are often superimposed, it is not always possible to identify uniquely the origins of specific discrepancies.

The attenuation problem has been successfully treated by an iterative approach, and the treatment of attenuation 'shadows' cast on the stratiform region by strong convective cells in the leading line lends considerable confidence to earlier estimates by Battan (1973) and Bénichou (1995), though a slightly improved relationship was derived here. It was found necessary to correct all reflectivity measurements over gauges, both to assure an adequate number of data points for the regressions, but also to assure more accurate radar rainfall estimates in the radar/gauge comparisons.

The expectation discussed in the Introduction for an approximate matching of fits for disdrometer comparisons and for the $Z_{\mathrm{e}}-R$ scatter plots is not upheld in this study. A comparison of power-law relations from the literature is shown in Table III. Comparison with the $Z_{\mathrm{e}}-R$ fits in Table II show a clear tendency for the prefactors produced here to be low. To be more quantitative here, we have computed the mean power-law prefactors for the $Z_{\mathrm{e}}-R$ relations for 13 cases in Table II with the mean prefactors for the $Z-R$ power-law relations in Table III. The result is $3.0 \mathrm{~dB}$ for the convective regions and $1.5 \mathrm{~dB}$ for the stratiform regions, with the $Z_{\mathrm{e}}-R$ on the prefactor low side in both cases. The explanation for this discrepancy is not well understood at present. Evidence that the radar is absolutely calibrated at the $1 \mathrm{~dB}$ level is presented in the Appendix, yet the $Z_{\mathrm{e}}-R$ prefactors are low relative to traditional $Z-R$ fits, even ones made earlier with disdrometers in Niamey, Niger. Evidence has been found more recently (through comparisons of reflectivity at two tilts over the same gauges) that the use of the lowest beam 
Table III. Summary of disdrometer $Z-R$ relationships from the literature.

\begin{tabular}{lcll}
\hline Convective $Z-R$ & Stratiform $Z-R$ & \multicolumn{1}{c}{ Investigator } & \multicolumn{1}{c}{ Measurement location } \\
\hline$Z=139 R^{1.43}$ & $Z=367 R^{1.3}$ & Tokay and Short (1996) & Kapingamarangi Atoll, Pacific Ocean \\
$Z=766 R^{1.14}$ & $Z=233 R^{1.01}$ & Atlas et al. $(1999)$ & Kapingamarangi Atoll. Pacific Ocean \\
$Z=99 R^{1.47}$ & $Z=252 R^{1.61}$ & & \\
$Z=588 R^{1.08}$ & $Z=88.7 R^{1.9}$ & & Darwin, Australia \\
$Z=334 R^{1.19}$ & $Z=278 R^{1.44}$ & & Mississippi, USA \\
$Z=233 R^{1.39}$ & $Z=532 R^{1.28}$ & Maki et al. $(2001)$ & Senegal \\
$Z=315 R^{1.38}$ & $Z=463 R^{1.4}$ & Uijlenhoet et al. $(2003)$ & \\
$Z=205 R^{1.43}$ & $Z=405 R^{1.28}$ & Nzeukou et al. $(2004)$ & \\
$Z=144 R^{1.51}$ & $Z=351 R^{1.24}$ & & Senegal \\
$Z=146 R^{1.53}$ & $Z=387 R^{1.25}$ & & Benin \\
$Z=153 R^{1.46}$ & $Z=352 R^{1.22}$ & & \\
$Z=162 R^{1.48}$ & $Z=385 R^{1.21}$ & Nzeukou et al. (2004) & \\
$Z=289 R^{1.43}$ & $Z=562 R^{1.44}$ & Moumouni et al. $(2008)$ & Top $Z$ - $R$ : squall lines only \\
$Z=343 R^{1.38}$ & $Z=468 R^{0.9}$ & Bottom $Z$ - $R$ : all types of system & \\
& & &
\end{tabular}
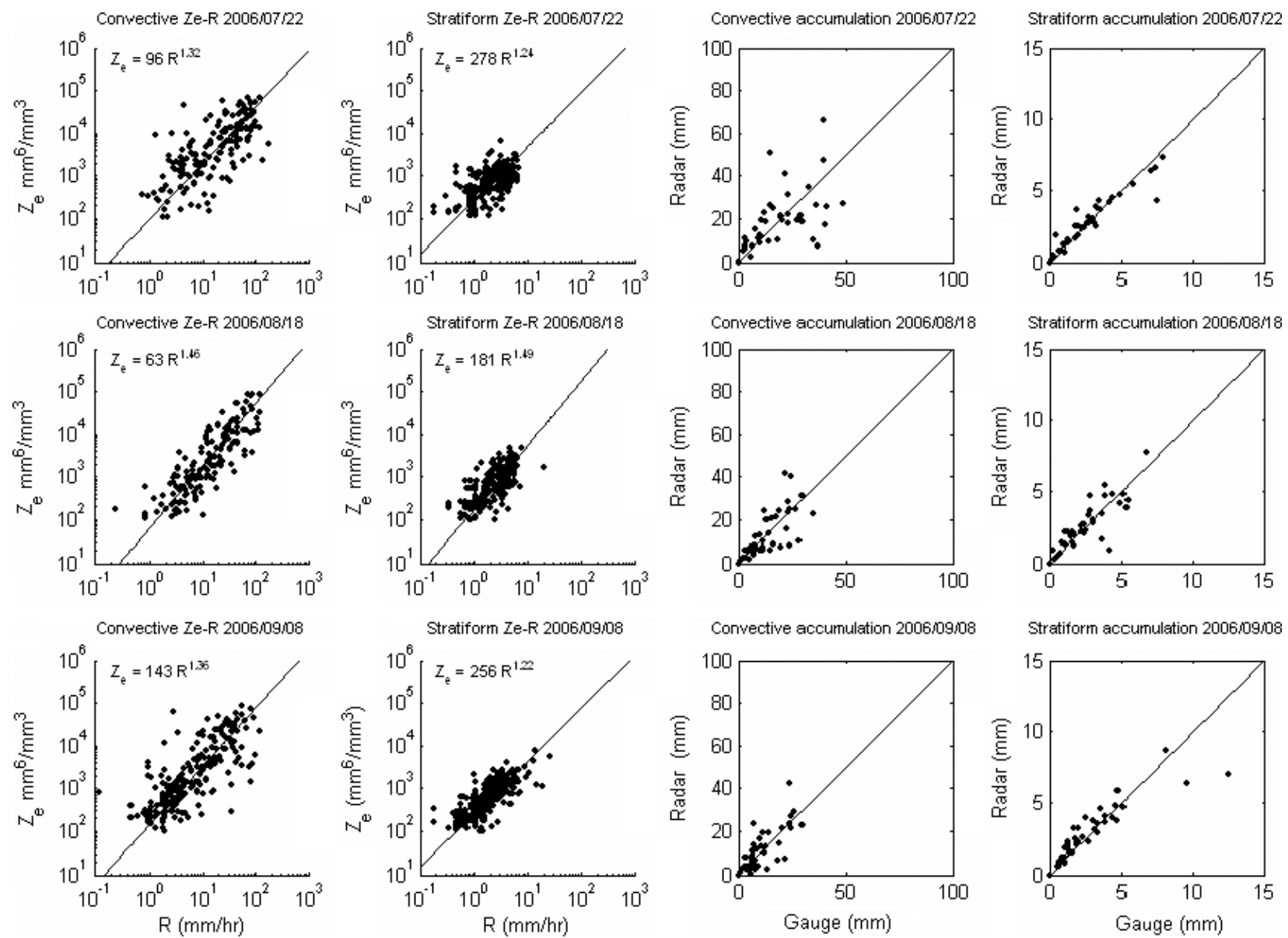

Figure 6. $Z_{\mathrm{e}}-R$ scatter diagrams for selected storms for convective and stratiform regimes (left-hand column), radar/gauge comparisons for convective storm totals (centre column), and radar/gauge comparisons for stratiform storm totals (right-hand column).

tilt $\left(0.57^{\circ}\right)$ in all of the gauge comparisons may be causing a $1-2 \mathrm{~dB}$ degradation in the reflectivity estimates for the radar, and this may account for part of the discrepancy here. This discrepancy does not find an explanation in the evaporation of rain or raindrop break-up in the boundary layer, both of which would tend to cause the gauges to read low relative to the radar measurement of reflectivity at higher altitude. We have also thought earlier that a larger C-band attenuation, such as that found by Atlas et al. (1993) in Darwin, Australia, could possibly account for the prefactor discrepancy, but as noted earlier, the attenuation was checked carefully here and found to be 
broadly consistent with the more modest levels reported in the literature (Battan, 1973; Bénichou, 1995). Recent measurements by Rickenbach et al. (2009), also making use of MIT radar data in Niger in the AMMA context (see Appendix), indicate agreement in absolute calibration at the $1 \mathrm{~dB}$ level for the majority of the pixel comparisons with the NASA TRMM radar in space, but the difference histogram is skewed toward positive differences, with the MIT radar reading low by a mean of $\sim 1-2 \mathrm{~dB}$ These results by themselves do not account for the prefactor discrepancy, but together with the beam loss effect, may explain the observed differences.

The existence of pronounced negative deviations (outliers) in the $Z_{\mathrm{e}}-R$ plots which were clearly associated with either pronounced temporal changes in the gauge observations, or with spatial gradients in the PPI scans in the vicinity of the gauge, have been associated with the systematic errors predicted for non-uniformly populated pulse resolution volumes and logarithmic receivers (Rogers, 1971). These sometimes notable outliers were removed from the $Z_{\mathrm{e}}-R$ scatter plots prior to fitting. Such effects are difficult if not impossible to correct for because one lacks detailed information on gradient structure. In other circumstances, the radar was found to be reading low when rain-gushes of order $100 \mathrm{~mm} / \mathrm{h}$ gauge rates were observed for some of these outliers, or a temporal aliasing problem was evident, with the rain arriving at a gauge near the middle of the 10-minute interval between radar sweeps over that gauge. The only way to remedy the loss of such events to the accumulated rainfall is to sacrifice on volume scans, and increase the repetition frequency of the low-level radar sweeps. Such a procedure was not undertaken during AMMA because of the interest in the vertical development of the convection.

The most notable contrast between convective and stratiform regimes in the analysis considered here was found in the radar/gauge comparison plots. The substantially tighter behaviour of the stratiform regime on all days examined is attributed to the greater spatial uniformity and more modest reflectivity of the stratiform region that served to suppress gradient effects and which also required substantially smaller attenuation correction (Figure 5). Another intriguing question raised by this study pertains to what physical processes are causing such large variance in $Z_{\mathrm{e}}-R$ relationship values from storm to storm (Table II).

Some guidance is in order for the use of these results in producing quantitative rainfall estimates for the convective and stratiform regimes of the squall lines investigated. First of all, the reflectivity data need to be corrected for attenuation following the procedure in section 3.3 before the $Z_{\mathrm{e}}-R$ relation is applied. The regime definition here is based on the analyses of individual reflectivity time series over individual gauges (Figures 2 and 3). It is not recommended that the same procedure be followed in transforming the substantially larger field of radar reflectivity at all other locations to rainfall or latent heating. The choice of minimum reflectivity in the transition region, a location usually clearly identified in individual PPI scans of these storms, was made for both a physical reason and a practical one. The practical choice enables a clear-cut separation of convective and stratiform for subsequent digital analysis.

\section{Conclusions}

The main results of this study can be summarized as follows:

(1) $Z_{\mathrm{e}}-R$ power-law fits have been determined for the convective and stratiform regions of squall lines in West Africa on a number of days. Methods for bias adjustment have been successfully implemented. Considerably variability is noted case-tocase, consistent with drop size measurements during AMMA. These relationships enable radar evaluations of rainfall and attendant latent heat release over areas substantially larger than covered by the gauges.

(2) Comparisons of radar and gauge measurements of storm total rainfall show substantially better agreement for the stratiform regime than the convective regime.

(3) Correction for attenuation at C-band is essential for satisfactory results. Workable iterative methods have been developed to implement these corrections.

(4) The prefactors in the $Z_{\mathrm{e}}-R$ power-law fits (Table II) are systematically smaller than prefactors for published $Z-R$ fits on disdrometer data (Table III). The reasons for this discrepancy are tentatively attributed to partial loss of beam energy in the use of the lowest radar tilt $\left(0.57^{\circ}\right.$, less than half the $3 \mathrm{~dB}$ beam width), and to the radar reading 1-2 dB low (based on the TRMM comparisons). This discrepancy fortunately does not impair the rainfall estimates using the radar data, and in this context it is important to emphasize that future users of the MIT radar data for quantitative rainfall estimates are advised to use the $Z_{\mathrm{e}}-R$ relations for specific days of interest in Table II, and also to make use of reflectivity measurements at the lowest elevation angle $\left(0.57^{\circ}\right)$ from which the $Z_{\mathrm{e}}-R$ relations were derived.

(5) The $Z_{\mathrm{e}}-R$ relationships derived here are limited in application to MIT radar data from its operation in 2006 and 2007, and should not be applied to reflectivity data from other AMMA radars such as those in Benin.

\section{Acknowledgements}

Discussions with D. Rosenfeld, D. Atlas, C. Ulbrich, R. Cifeli and S. Rutledge on the treatment of C-band attenuation are appreciated. R. Boldi provided important assistance on the different approaches to least-squares fitting. Discussions of a more general nature on radar/gauge comparisons with D. Atlas, P.Austin, S.Geotis (deceased), 
R. Lhermitte, D. Rosenfeld, H. Sauvageot, M. Steiner and I. Zawadzki are also acknowledged. Eyal Amitai provided valuable advice on the calculation of bias-free $Z_{\mathrm{e}}-R$ relationships. The ARM team in Niamey (K. Nitschke and M. Alsop) provided helium and balloons for sphere calibrations in Niamey. J. Lutz, A. Siggia, J. Seltzer, S. Copeland and the late M. Couture prepared the radar for shipment and installation in Africa. S. Salou, M. Abdoulaye and C. Owbandowaki hosted the radar operation at l'Armée de l'Air, the Niger Air Force Base. Support for the radar operation in Africa came from NASA Hydrology (Jared Entin) and from RIPIECSA (Arona Diedhiou). Chris Thorncroft provided enthusiastic support for the radar funding. We also thank the many AMMA and RIPIECSA participants for their contribution in the round-the-clock operation of the radar for two wet seasons. E.R. Williams and B. Russell were supported in this study by a grant from the Climate Dynamics Program of the US National Science Foundation (ATM 0734806).

\section{Appendix}

\section{Calibration of Mit Radar with Metal Spheres}

\section{A1. Theoretical Basis}

The radar is absolutely calibrated with a metal sphere whose radar cross-section ( $\sigma$ with units $\mathrm{m}^{2}$ ) is accurately known. The dimensionless scattering parameter for a sphere of radius $r$ is $2 \pi r / \lambda$, and when this number is large, the cross section $\sigma$ becomes the geometrical crosssection of the sphere, $\pi r^{2}$. The calibration sphere is a point target for the radar, unlike the volume target $\eta$ (with units $\mathrm{m}^{2} / \mathrm{m}^{3}$ ) of raindrops whose accurate reflectivity $Z$ is desired for the measurement of rainfall. For a volume target whose spherical scatterers conform to the Rayleigh regime (diameter $D$ small in comparison to a wavelength $\lambda$ ), the volume reflectivity $\eta$ is given by (Battan, 1973; equation 4.24):

$$
\eta=\frac{\pi^{5}|k|^{5} Z}{\lambda^{4}} \quad \mathrm{~m}^{2} / \mathrm{m}^{3}
$$

It is convenient to form a range-dependent volume target for the calibration sphere, given simply by

$$
\eta=\sigma / P R V \quad \mathrm{~m}^{2} / \mathrm{m}^{3}
$$

where $P R V$ is the range-dependent pulse resolution volume, given by (Battan, 1973; equation 4.7)

$$
P R V=\pi \theta \varphi h / 8 \quad \mathrm{~m}^{3}
$$

in which $\varphi$ is the horizontal $(3 \mathrm{~dB})$ beamwidth of the radar antenna, $\theta$ is the vertical beamwidth, and $h$ is the radar pulse length.
Values for the relevant radar parameters are given below.

$$
\begin{aligned}
& \lambda=5.37 \mathrm{~cm} \\
& 2 \pi r / \lambda=8.9(7.6 \mathrm{~cm} \text { diameter sphere }) \\
& 2 \pi r / \lambda=17.8(15.2 \mathrm{~cm} \text { diameter sphere }) \\
& h=300 \mathrm{~m}(1 \mu \mathrm{s} \text { pulse length }) \\
& \varphi=1.62^{\circ}=0.0283 \mathrm{rad} \\
& \theta=1.52^{\circ}=0.0265 \mathrm{rad}
\end{aligned}
$$

Equating expressions (A1) and (A2), with the use of (A3) and the values for the radar parameters, enables a determination of the radar reflectivity $Z$ (in conventional units for reflectivity, $\mathrm{mm}^{6} / \mathrm{m}^{3}$ ) expected from the full radar equation for a calibration sphere at an arbitrary radar range $\mathrm{R}$, and yields the prediction

$$
Z=105 r^{2} / \mathrm{R}^{2} \quad \mathrm{~mm}^{6} / \mathrm{m}^{3}
$$

with sphere radius $r$ in centimetres and radar range $\mathrm{R}$ in kilometres.

\section{A2. Radar Measurements on Tethered Metal Spheres}

Calibration measurements on metal spheres raised with tethered hydrogen-filled neoprene balloons, at heights of several hundred metres, were attempted on multiple occasions in both the 2006 and 2007 field campaigns in Niamey.

The absolute pointing of the radar antenna had been reliably established earlier in each field campaign with Sun-tracking procedures enabled by SIGMET radar software. For each sphere calibration measurement, a theodolite was set up on the radar tower directly beneath the antenna, and was used in manual mode throughout the measurements to establish the azimuth and elevation angles of the calibration sphere to aid in the pointing of the radar antenna, and the maximization of the radar return.

The most successful radar calibration was performed on 22 September 2007, when measurements were made on both $6^{\prime \prime}$ diameter $(r=7.62 \mathrm{~cm})$ and $12^{\prime \prime}$ diameter $(r=$ $15.2 \mathrm{~cm}$ ) aluminium calibration spheres (manufactured by Carlstrom Pressed Metals, Worcester, Massachusetts). The best estimate of the radar range $\mathrm{R}$ is $2.97 \mathrm{~km}$. A comparison of predictions based on equation (4) with the radar measurements using the SIGMET A-Scope program, in which the range-normalized return from the metal sphere target is given in dBZ units, are shown below

$\begin{array}{lll} & \text { Predicted } & \text { Measured } \\ 6^{\prime \prime} \text { sphere } & 28.4 \mathrm{dBZ} & 28.3+/-0.5 \mathrm{dBZ} \\ 12^{\prime \prime} \text { sphere } & 34.4 \mathrm{dBZ} & 35.5+/-0.5 \mathrm{dBZ}\end{array}$

Agreement between theory and measurement on the $6^{\prime \prime}$ sphere is excellent. For reasons we do not understand, the clean $6 \mathrm{~dB}$ difference in radar cross-section expected for $6^{\prime \prime}$ and $12^{\prime \prime}$ spheres was not exactly realized, and the 


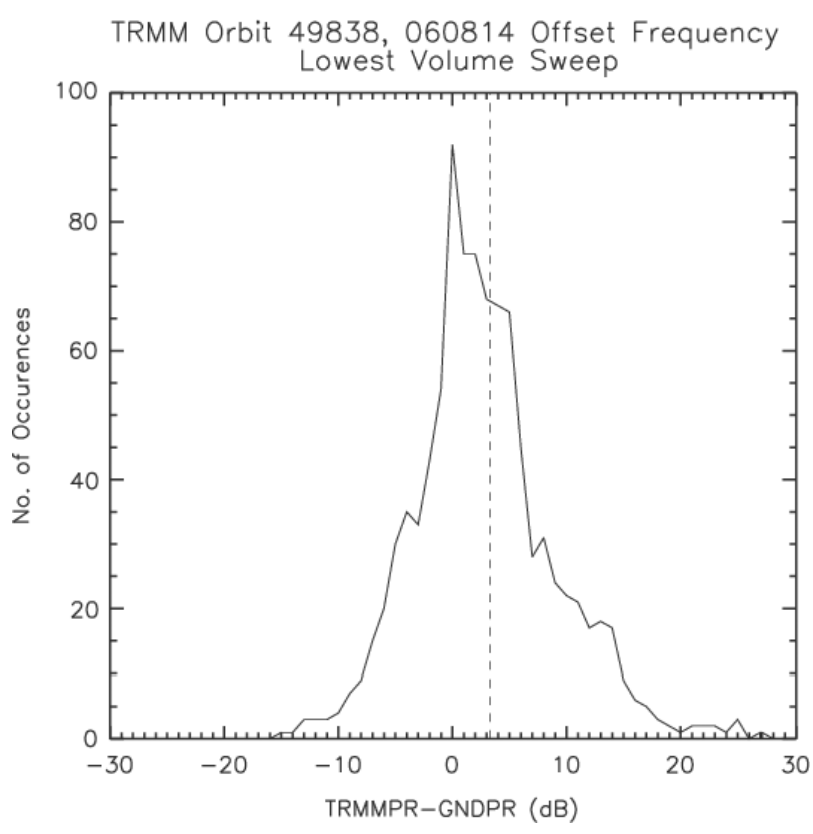

Figure A1. Histogram comparison of point comparisons of TRMM precipitation radar in space and the MIT radar in Niamey, Niger for ground-based observations in the lowest radar tilt $\left(0.57^{\circ}\right)$.

larger sphere was systematically larger than expected. Nevertheless, the measured cross-section for the larger sphere is still within $1.1 \mathrm{~dB}$ of the prediction, about as good as one can expect in typical calibration measurements of this kind. Calibration measurements of a similar kind performed in 2006 were also found to agree at the nominal $+/-1 \mathrm{~dB}$ level.

An additional check on the calibration of the MIT radar has been afforded by detailed comparisons with the 2A25 dataset from the TRMM precipitation radar in space (Rickenbach et al., 2009). These comparisons involved point-to-point comparisons between the threedimensional volume scan information from the radar and the ground track data from the TRMM precipitation radar. Figure A1 shows the comparisons on 14 August 2006. The most likely offset is $0 \mathrm{~dB}$, but the distribution is noticeably skewed to positive values, with a mean point-to point difference of $3.1 \mathrm{~dB}$, suggesting that the radar is reading low in the upper tilts by $1-2 \mathrm{~dB}$. This may also provide some explanation for the discrepancy in power-law prefactors addressed in the Discussion section.

\section{References}

Ali A, Lebel T, Amani A. 2005. Rainfall estimation in the Sahel. Part I: Error function. J. Appl. Meteorol. 44: 1691-1706.

Atlas D, Rosenfeld D, Wolff DB. 1993. C-band attenuation by tropical rainfall in Darwin, Australia using climatologically tuned $Z_{\mathrm{e}}-R$ relations. J. Appl. Meteorol. 32: 426-430.

Atlas D, Ulbrich CW, Marks Jr FD, Amitai E, Williams CR. 1999. Systematic variation of drop size and radar-rainfall relations. $J$. Geophys. Res. 104: 6155-6169.

Austin PM. 1987. Relation between measured radar reflectivity and surface rainfall. Mon. Weather Rev. 115: 1053-1070.

Balme M, Vischel T, Lebel T, Peugeot C, Galle S. 2006. Assessing the water balance in the Sahel: Impact of small scale rainfall variability on runoff. Part 1: Rainfall variability analysis. J. Hydrol. 331: $336-348$.
Battan LJ. 1973. Radar observation of the atmosphere. University of Chicago Press.

Bénichou H. 1995. 'Utilisation d'un radar météorologique bande $C$ pour la mesure des pluies au Sahel: Étude du phénomène d'atténuation'. Univ. J. Fourier: Grenoble.

Calheiros RV, Zawadzki II. 1987. Reflectivity-rain rate relationships for radar hydrology in Brazil. J. Clim. Appl. Meteorol. 26: $118-132$.

Chamsi N. 1992. 'Estimation des précipitations à partir de la réflectivité radar dans les systèmes convectifs tropicaux'. Doctoral thesis, Université Paul Sabatier, Toulouse, France, 110 pp.

Delrieu G, Hucke L, Creutin JD. 1999. Attenuation in rain for X- and C-band weather radar systems: Sensitivity with respect to the drop size distribution. J. Appl. Meteorol. 38: 57-68.

Engholm CD, Williams ER, Dole RM. 1990. Meteorological and electrical conditions associated with positive cloud-to-ground lightning. Mon. Weather Rev. 118: 470-487.

Geotis SG. 1975. 'Some measurements of the attenuation of 5$\mathrm{cm}$ radiation in rain'. $\mathrm{Pp}$ 63-66 in Preprints, $16^{\text {th }}$ Conf. on Radar Meteorology, Houston, Texas, 22-24 April 1975. American Meteorological Society.

Hildebrand PH. 1978. Iterative correction for attenuation of $5 \mathrm{~cm}$ radar in rain. J. Appl. Meteorol. 17: 508-514.

Hitschfeld W, Bordan J. 1954. Errors inherent in the radar measurement of rainfall at attenuating wavelengths. J. Meteorol. 11: 58-67.

Le Barbé L, Lebel T. 1997. Rainfall climatology of the HAPEXSahel region during years 1950-1990. J. Hydrol. 188-189: 46-73.

Maki M, Keenan TD, Sasaki Y, Nakamura K. 2001. Characteristics of the raindrop size distribution in tropical continental squall lines observed in Darwin, Australia. J. Appl. Meteorol. 40: $1393-1412$.

Moumouni S, Gosset M, Houngninou E. 2008. Main features of rain drop size distributions observed in Benin, West Africa, with optical disdrometers. Geophys. Res. Lett. 35: L23807, DOI: 10.1029/2008GL035755.

Nievergelt Y. 1994. Total least squares: State-of-the-art regression in numerical analysis. SIAM Review 36: 258-264.

Nzeukou A, Sauvageot H, Ochou AD, Kebe CMF. 2004. Raindrop size distribution and radar parameters at Cape Verde. J. Appl. Meteorol. 43: $90-105$.

Rickenbach TM, Rutledge SA. 1998. Convection in TOGA COARE: Horizontal scale, morphology, and rainfall production. J. Atmos. Sci. 55: $2715-2729$.

Rickenbach TM, Nieto Ferreira R, Guy N, Williams ER. 2009. Radar-observed squall line propagation and the diurnal cycle of convection in Niamey, Niger during the 2006 African Monsoon and Multidisciplinary Analyses Intensive Observing Period. J. Geophys. Res. 114: D03107, DOI:10.1029/2008JD010871.

Rogers RR. 1971. The effect of variable target reflectivity on weather radar measurements. Q. J. R. Meteorol. Soc. 97: 154-167.

Rosenfeld D, Atlas D, Wolff DB, Amitai E. 1992. Beamwidth effects on $\mathrm{Z}-\mathrm{R}$ relations and area-integrated rainfall. J. Appl. Meteorol. 31: 454-464.

Rosenfeld D, Wolff DB, Atlas D. 1993. General probability-matched relations between radar reflectivity and rain rate. J. Appl. Meteorol. 32: $50-72$.

Smith JA, Krajewski WF. 1991. Estimation of the mean field bias of radar rainfall estimates. J. Appl. Meteorol. 30: 397-412.

Steiner M, Smith JA, Burgess SJ, Alonso CV, Darden RW. 1999. Effect of bias adjustment and rain gauge data quality control on radar rainfall estimation. Water Resour. Res. 35: 2487-2503.

Tokay A, Short DA. 1996. Evidence from tropical raindrop spectra of the origin of rain from stratiform versus convective clouds. J. Appl. Meteorol. 35: 355-371.

Uijlenhoet R, Steiner M, Smith JA. 2003. Variability of raindrop size distributions in a squall line and implications for radar rainfall estimation. J. Hydrometeorol. 4: 43-61.

Williams ER, Weber ME, Orville RE. 1989a. The relationship between lightning type and convective state of thunderclouds. J. Geophys. Res. 94: 13213-13220.

Williams ER, Geotis SG, Bhattacharya AB. 1989b. A radar study of the plasma and geometry of lightning. J. Atmos. Sci. 46: 1173-1185. 
Williams ER, Rutledge SA, Geotis SG, Renno N, Rasmussen E, Rickenbach T. 1992. A radar and electrical study of tropical 'hot towers'. J. Atmos. Sci. 49: 1386-1395.

Yuter SE, Houze Jr RA. 2000. The 1997 Pan American Climate Studies Tropical Eastern Pacific Process Study. Part I: ITCZ region. Bull. Am. Meteorol. Soc. 81: 451-481.
Zawadzki I. 1982. The quantitative interpretation of weather radar measurements. Atmos. - Ocean 20: 158-180.

Zawadzki I, Desrochers C, Torlaschi E. 1986. 'A radar-raingage comparison'. Pp 121-124 in Vol. I, $23^{\text {rd }}$ Conference on Radar Meteorology, Snowmass, Colorado, 22 - 26 September 1986. American Meteorological Society. 